\title{
GCU
}

Glasgow Caledonian

University

University for the Common Good

\section{Nursing students' first placement: peripherality and marginality within the community of practice \\ Molesworth, Mark}

Published in:

Journal of Nursing Education

DOI:

10.3928/01484834-20161219-07

Publication date:

2017

Document Version

Author accepted manuscript

Link to publication in ResearchOnline

Citation for published version (Harvard):

Molesworth, M 2017, 'Nursing students' first placement: peripherality and marginality within the community of practice', Journal of Nursing Education, vol. 56, no. 1, pp. 31-38. https://doi.org/10.3928/01484834-20161219-07

\section{General rights}

Copyright and moral rights for the publications made accessible in the public portal are retained by the authors and/or other copyright owners and it is a condition of accessing publications that users recognise and abide by the legal requirements associated with these rights.

Take down policy

If you believe that this document breaches copyright please view our takedown policy at https://edshare.gcu.ac.uk/id/eprint/5179 for details of how to contact us. 
For many students the first placement is a momentous and daunting experience (Sharples, 2009). It leads to a

3 shift in the identity of students as their attitude and practices change (Miller et al., 2008). There is often a contrast

4 between nursing students' expectations at the start of their education and their actual experiences during placement

5 (Hoel, Giga and Davidson, 2007). This mismatch can lead to attrition (Cook, 2009) which is often highest in the first

6 practice learning opportunity (Aston and Hallam, 2011). Indeed, placement experiences count as a factor in a third of

7 all cases of withdrawal from programmes in Scotland (Royal College of Nursing, 2008) and high levels of attrition

8 from nursing programmes are a concern from both Scottish and international perspectives (Rodgers, Stenhouse,

$9 \quad$ McCreadie and Small, 2012).

This qualitative study aims to gain new insights into first placement experiences within pre-registration nurse education from the perspective of student nurses. Key concepts from the social learning theory communities of practice (CoP) (Lave and Wenger, 1991; Wenger, 1998) provide a framework for the analysis of these experiences.

This novel approach provides information which may be useful to those with a stake in nurse education, particularly in relation to preparing and supporting students within practice settings.

\section{Literature review}

Student nurses' experiences of the first placement vary widely and are dependent upon many factors. One of the most important influences within UK practice settings is that of the mentor, a registered nurse who meets the Nursing and Midwifery Council (NMC) mentor standard (NMC, 2008). Within the Scottish context those carrying out the role of mentor for pre-registration nursing students are supported by Practice Education Facilitators (PEF) (National Health Service Education for Scotland (NES), 2013). The PEF role was created in 2004 in recognition that mentors required support to help them negotiate the complex decision making processes associated with the supervision and assessment of student nurses (NES, 2013). Whilst giving direct care in the practice setting at least $40 \%$ of a student's time must be spent being supervised (directly or indirectly) by a Mentor/Practice Teacher (NMC, 2008). Mentors, with day to day responsibility for learning, are often the key to students' learning experience in practice (O'Driscoll, Allan and Smith, 2010). The role of the mentor in relation to the nature and quality of placement experiences during nurse education is well documented in the literature (e.g. Baglin and Rugg, 2010; Gray and Smith, 2000; Myall, Levett-Jones and Lathlean, 2008). It is a position which is complex and requires a high level of commitment, energy and time (Atkins and Williams, 1995) and the vast majority of students experience nurturing, caring clinical environments and staff relationships (Thomas, Jack and Jinks, 2012).

When mentoring, an important aspect of creating a supportive learning environment is familiarising the student with the placement area by connecting the student to the culture, staff and community on the ward 
effectively as they are empowered through being understood and encouraged (Bradbury-Jones, Sambrook and Irvine, 2007). In contrast, a sense of disempowerment can arise from disrespect shown to them by other members of the team. Being a peripheral participant within the power structure of a community of practice can lead to feelings of anxiety, particularly if the student feels they have been demeaned (Melincavage, 2011). Perceptions of being made unwelcome or ignored and simply being referred to as 'the student' is an experience which many students find upsetting (Hoel, Giga and Davidson, 2007). Gibbons, Dempster and Moutray (2008) investigated the issue of stress in their qualitative study of 16 final year nursing students. The study found that sources of distress included the attitudes of some staff, working on under-staffed wards and student status on placement. Not establishing a rapport with the clinical team and being treated in a disrespectful manner can lead to thoughts of leaving the course (Hamshire, Willgoss and Wibberley, 2013).

CoP is a social learning theory first introduced by Lave and Wenger (1991) and later developed substantially by Wenger (1998). It proposes that learning is integrated in practice and occurs through engagement within the CoP (Lave \& Wenger, 1991). CoP is one of the most influential ideas to have emerged in the social sciences during recent years (Blackmore, 2010) and is particularly applicable to health settings (Eraut, Alderton, Cole and Senker, 2000; Sayer, 2014). Indeed, learning to become a nurse and the development of professional capital is often situated within CoP (Burkitt, Husband, MacKenzie, Tom and Crow, 2000; Gobbi, 2010). Grealish and Ranse (2009) found that for first year student nursing students, learning to be a nurse is less dependent upon the various qualities of the clinical environment and more dependent upon participation in the CoP. Wenger (1998) argues that identities are constituted through both participation and non-participation within CoP. It is here that marginality and peripherality have an important role in influencing the individual's identity as well as their trajectory in relation to the 'inside' or 'outside' of the CoP. Morley (2016) suggests that the thoughtful learning model for practice put forward by Wenger provides a recognisable learning structure that is applicable to placement learning within nurse education.

\section{Method}

Seventeen first year nursing students out of a potential seventy were recruited from a campus at a Scottish University using purposive sampling. The sample group was selected on the basis that cohort had just returned to university following their first placement of an undergraduate nursing programme. The first placement takes place after approximately ten weeks of theory and consists of a four-week introductory placement within a wide range of areas including acute adult and mental health in-patient settings, nursing homes, and community hospitals. The theoretical content delivered prior to the placement includes the role of the nurse and the professional behaviours and attributes expected of student nurses. Students also learn about other issues such as team working, communication and the mentoring process as well as how to access support whilst in placement. All students should have meeting with a member of the academic faculty during their first practice placement on a minimum of one occasion to monitor their 
progress and provide support as necessary. Prior to attending the placement area students are provided with information about the type of placement they are going to, along with the health and social care needs of services users. The main and associated learning opportunities are provided in advance as well as resources and additional reading to help them prepare for commencing the placement.

Located in the Constructivist-Interpretivist paradigm this inquiry adopts the principle that there are multiple, equally valid and socially constructed realities (Ponterotto and Grieger, 2007). Aligned with this approach are the data collection methods of individual and multi-person qualitative interviewing (Rubin and Rubin, 2005). In total five individual interviews and two focus groups, with six individuals in each, were undertaken. The individual interviews lasted approximately an hour and the focus groups lasted an hour and a half to two hours. An interview guide was used in a non-rigid manner to support a semi-structured interviewing approach (Flick, 2014). The interview guide used for this study featured questions which prompted students to discuss their experiences in relation to areas of the first placement, such as how prepared they felt and their relationships with staff during the placement. The main questions in the interview guide are highlighted in Table 1. A responsive approach was taken by the interviewer to develop depth and detail in relation to the issues participants described (Rubin and Rubin, 2012).

Potential participants were initially emailed details about the inquiry by the researcher to establish if they were interested in finding out more information. Following this they had the opportunity to attend a face to face meeting with the researcher to ask questions and be provided with the Participant Information Sheet. They were also asked whether they would prefer an individual interview or to be part of a focus group. Following a two week 'cooling off' period those who were still interested in participating were asked to sign a consent form. No coercion or pressure was applied and potential participants could freely choose whether or not to be involved. There are 'power plays' inherent in all qualitative research interactions (Brinkmann and Kvale, 2005) and these may be amplified in circumstances where there is an existing power differential, such as the one between student and lecturer. To try to minimise these issues participants were recruited from a campus where the researcher was not carrying out any learning, teaching, assessment or pastoral activities and did not have any prior relationship with potential participants. Prior to participant recruitment ethical approval for the inquiry was obtained from the University Ethics Committee.

\section{Data Analysis}

Following the data collection, the audio recordings were transcribed verbatim, an aspect of becoming familiar with the data (Creswell, 2009). The data analysis then followed the process of deductive content analysis set out by Elo and Kyngas (2008). During the preparation phase the unit of meaning was selected as the unit of analysis and several readings of the transcripts ensured familiarity with the data. Next the analysis followed what Elo and Kyngas (2008) describe as an unconstrained matrix of analysis. This enables subcategories to emerge using an inductive approach whilst still working within the bounds of deductive main categories (Elo and Kyngas, 2008). Two 
pre-determined categories were derived was designed using Wenger's (1998, p.167) model which sets out the "relations of participation and non-participation" present within a CoP. This model represents the relationship between peripherality, as an inbound or enabling form of non-participation in contrast with marginality as an outbound or preventative form of non-participation. Table 2 displays these deductive categories along with the inductive sub-categories. Using predetermined theoretical concepts to structure the analysis in this manner is different to the inductive approaches common to qualitative research. Braun and Clarke (2006) explain that theoretical or deductive analyses are 'top down' approaches and are therefore more explicitly analyst-driven than inductive approaches. Brinkmann and Kvale (2015) highlight that this approach has the potential to bring forth new dimensions on seemingly familiar phenomena. However, there is a limitation inherent to this approach in the sense that the researcher has approached the data with an informed but strong bias (Hsieh and Shannon, 2005).

\section{Findings}

The findings are grouped under each sub-category with those aligned with experiences of peripherality presented first, followed by those aligned with experiences of marginality.

The mentor as a factor in experiences of peripherality.

Peripherality was apparent within many of the students' attempts to engage with the activities of the CoP.

Often they did not have direct access to learning opportunities and remained dependent upon the mentor who had significant influence over their participation and/or non-participation. This sometimes leads to a perceived requirement to build up a rapport of respect with the mentor as a means to improve the student's ability to negotiate their learning:

I was a bit worried about negotiating my learning [...]-but I think I did quite well with it because I think I built up a rapport of respect with the nurses so that they would let me come in and do the work with them. (Focus Group 2)

There is a sense that students recognise that non-participation is just as important as participation in enabling them to develop effective relationships. For example, participants described that it was necessary to understand the demands on the mentor and minimise any disruption to their activities:

I had a good relationship with my mentor, I picked up from day one when she was busy (Interview 1)

This means operating at the periphery but being ready to take advantage when the mentor facilitated an opportunity for participation. Often this was a process of negotiation which was led by the mentor: ...'[Mentor] I'm not going to talk you through that medicine administration but I'll talk you through another one later', so we did negotiate all the time. (Focus Group 2)

\section{Other staff as a factor in experiences of peripherality.}



who change their practice in the presence of the student. Some of them would show me, they would be like 'oh we'd better do it properly since you're here' and they would show me how to do it properly ... (Focus Group 1)

Although it may be considered a form of participation, it is one which maintains the student's peripherality within the CoP. It also highlights that there are practices within the CoP which are hidden from 'outsiders' and implies that to be a more central member there is an expectation that certain aspects of poor practice need to be adopted or at least ignored. Indeed, From Wenger's (1998) perspective it is worth noting that while the CoP is a crucial locus of learning this does not imply that the process is intrinsically benevolent.

Patients, carers and family as a factor in experiences of peripherality.

The students' peripheral status also appeared to influence the relationships that were developed with patients and visitors. For many of the students involved this was apparent as both a set of expectations on the part of patients and as a means of special access to them: other members of the $\mathrm{CoP}$ within the placement. This indicates that while the relationship with the mentor is The patients accept you as you are and I feel that in the student nurse - patient relationship I know where I stand and I feel confident I can build relationships. (Interview 5) other staff considered 'difficult'. In addition, peripherality provided opportunities to develop relationships with relatives that are not available to other members of the CoP: I think they were quite confrontational with the nursing staff... and the medical staff as well because they were at odds with what they were recommending what they wanted for this lady but I was talking to them purely on a personal level. (Interview 2)

This indicates that in some cases being on the periphery actually has the potential to enhance students' relationships with patients and relatives.

The mentor as a factor in experiences of marginality.

As might be expected when the mentor did not provide access to the work of the CoP this created problems: I had a bit of trouble with my mentor [...] I got on great with my mentor - she was really really nice, but in my first week and second week I was kind of just left to wander about ... and it's not that they weren't nice it was like they had better things to do rather than make sure I was kept busy. (Focus Group 1) Despite the importance of the relations with the mentor by far the biggest source of marginalisation was with important in gaining access to learning opportunities it does not necessarily grant access to the wider activities of the CoP. This is demonstrated in the example below: 
I struggled a bit with some of the staff, if you weren't working with your mentor sometimes you got a bit lost and some of the nurses weren't too keen to sort of help you [...] being on my first placement I just tended to sort of go off and sit there and not know what to do and end up spending hours not doing anything really. (Interview 3)

Other staff as a factor in experiences of marginality.

In some cases, this went beyond not facilitating access to learning opportunities to creating difficulties for students. This may be through subtle forms of exclusion, both in the ward environment and during breaks, to issues which indicate an underlying power struggle: [I was] finding my place in the hierarchy ... some people are absolutely great and welcome the student, other people go out of their way to make students feel difficult. (Interview 5)

Additionally, there was the potential for marginalisation by the way that ideas and suggestions were considered by other staff within the CoP. Where students' contributions were not considered by the CoP this was a marginalising form of non-participation: longer term.

$$
\text { 'you're only a student'. (Focus Group 2) }
$$

An approach which depersonalises the student by other members of the CoP can also be a source of marginalisation:

... it seems that they don't want to teach me ... and they would call me 'the student' rather than by my name. (Interview 4)

\section{Liaison lecturer as a factor in experiences of marginality.}

The Liaison Lecturer for the placement area is responsible for responding to placement issues referred by the student. However, some participants described how they did not receive any contact from the Liaison Lecturer whilst in placement. Even where there were opportunities to raise a particular concern, such as the one quoted from interview 4 above, there was a reluctance to raise it with the designated lecturer:

I think it would have made the situation worse as well if he'd have come in and said 'oh these nurses aren't doing this'. (Interview 4)

A relevant factor is that the student was not visited by the liaison lecturer until the final day of the placement. An earlier visit may have facilitated the opportunity to agree the best approach to issues of marginalisation being experienced by the student. A lack of external support has the potential to further isolate students experiencing difficulties and may reduce the likelihood of problems within the placement area being resolved, both in the short and

\section{Discussion}


Wenger, 1991). It is the central process of situated learning: learning that is a process of participation CoP. In this context peripherality is a positive term as it suggests an opening, a way of gaining access to sources for understanding through growing involvement. As a student moves towards more-intensive participation, peripherality is an empowering position (Lave and Wenger, 1991). Where the student is kept from participating more fully it is a disempowering position and may become a source of marginalisation. Wenger $(1998, \mathrm{p} .166)$ describes that "peripherality and marginality both involve a mix of participation and non-participation, and the line between them can be subtle". In the case of peripherality some degree of non-participation is necessary as this enables the participant to access the CoP. In the case of marginality, the non-participation comes to define a restricted, rather than enabling, form of participation. The mix of participation and non-participation reflects our power as individuals to define and affect our relations with the rest of the world (Wenger, 1998).

The findings illuminate the complex CoPs that student nurses find themselves attempting to navigate during the first placement. For the participants involved in this study it is the relationships within the CoP that are central to providing or limiting access to learning opportunities. These findings reflect a complex picture of relations and power differentials within nursing placements. While CoPs may provide social infrastructures that foster learning they can also be a source of distress and marginalisation for the novice (Le May, 2009). The findings highlight the central role of the mentor as important in facilitating access to the activities of the CoP. Mentors are often in key positions within the CoP which supports their important role in the legitimate peripheral participation of students (Field, 2004). The importance of the student-mentor relationship is apparent within the findings of this study. Those who had mentors that did not facilitate participation, particularly at the start of the placement, cited very difficult experiences including complete marginalised from the CoP. If these types of situations remain unresolved it is likely to damage the identity of the student nurse as well as their progress on the course. Indeed, unsupportive mentors have been found to be a factor in students considering leaving as they struggled to integrate within the placement team (Hamshire, Willgoss and Wibberley, 2013). underpinned with a degree of compliance on the part of the student. Conformity and compliance is often perceived to be an important aspect of being accepted (Levett-Jones and Lathlean, 2009). It is also an acknowledgement by the students of the challenges the mentor may face, particularly in relation to competing demands and time (McIntosh, Gidman and Smith, 2014). Compliance may be positive from a learning perspective as the demands of the mentor can take reluctant students beyond their "limitations, likes and dislikes, and may result in their reaching understandings of their own" (Wenger, 1998, p.85). However, compliance can influence the student's ability to negotiate within the CoP and increase their risk of marginalisation. PEFs provide support for mentors to ensure effective supervision, 
assessment and decision making and are therefore well placed to address issues such as those highlighted above. In doing so they are able to enhance the practice learning environment and improve the learner support and experience (NES, 2013). Participation within the $\mathrm{CoP}$ is not concerned with affiliation to the mentor alone, it concerns the whole community and sponsorship, usually through the mentor, to permit the student to become an acknowledged member of the CoP (Spouse, 1998). Despite the important role of the mentor by far the largest source of marginality within the findings was other staff within the CoP. Some of the findings described earlier reflect a study by Hathorn, Machtmes and Tillman (2009) which found that nurses admitted to acting out negative attitudes by being condescending, ignoring, or being judgmental to the student nurses. These issues, as potential sources of marginalisation, can reduce access to the $\mathrm{CoP}$ and in turn limit learning opportunities. Indeed, Wenger (1998) is clear that when a community rejects a newcomer for some reason that person has a difficult time learning. Where the student's ideas are ignored or they are depersonalised this leads to marginality and has a potentially detrimental effect on the identity of the individual. Thrysoe, Hounsgaard, Bonderup and Wagner (2010) found that being overlooked in conversations between nurses often led to anger and frustration in the students, resulting in greater passivity. feeling like a 'pair of hands'. This has previously been found as an issue, particularly where there are staff shortages (Myall, Levett-Jones and Lathlean, 2008: 1840). Staff behaviour may be an unconscious attempt to 'toughen up' students to accept the unvarnished truth of what clinical practice is really like (Thomas, Jack and Jinks, 2012). However, this may not come as a surprise to Lave and Wenger (1991: 110) who explain that 'newcomers' tasks are short and simple tending to be positioned at the end of branches of work processes'. According to Eraut (2002) novices within a CoP may find themselves engaged in long periods of routine, repetitive work that has long ceased to be a source of learning due to the requirements of the institution. Lecturer. Nurse Lecturers at the university are designated specific practice placement areas and act as the link between the university and the placement setting. The university provides specific quality standards that Liaison Lecturers are expected to meet and these are underpinned by guidance from relevant professional and academic bodies (e.g. NES, 2008; NMC, 2008; The Quality Assurance Agency for Higher Education, 2012). There are also robust procedures for students to evaluate their learning experiences within practice settings. Lecturers typically visit students on their first placement a minimum of once but may visit more regularly if the student requires additional support. Students in the study highlight inconsistencies in terms of what they experienced with some receiving support and guidance and others describing that they did not have any contact with the relevant lecturer. This finding reflects the inconsistencies found in an inquiry by Collington, Mallik, Doris and Fraser (2012) which had a specific focus on the role of the 
liaison lecturer. They found that visits to midwifery students by liaison lecturers was seen as valuable by students but seemed to depend upon the individual lecturers more than actual course structure. The liaison lecturer is important for enabling the mentor/student relationship (Price, Hastie, Duffy, Ness and McCallum, 2011) and where links are not effective it may be more difficult manage issues such as marginality and any negative impact on the learning experience that may result.

Learning is inherently stimulated by the needs of patients, who play a key role in the accumulation of professional practice (Gobbi, 2010). Most participants emphasised the importance of their relationships with patients and how they associated these with notions of being or becoming a nurse. Participant's peripherality within the CoP seemed to make them more accessible to the patients. This appeared to go beyond the additional time they might have available to the actual configuration of the interaction between students and patients. Suikkala, Leino-Kilpi and Katajisto (2008) explored the relationship between student and patient and emphasise the central importance this relationship in terms of students' clinical learning. The same authors later explored this relationship from the perspective of patients and found that the student-patient relationship has a positive impact on patient's improved health and commitment to self-care (Suikkala, Leino-Kilpi and Katajisto, 2009). Patients also recognised the positive influence that this relationship can have on the student's increased confidence and self-esteem. From the perspective of $\mathrm{CoP}$, the student-patient relationship is likely to be influential for the emerging identity of the student nurse, and for those who experience marginality within the placement it may even counter the impact of this to an extent. However, potential difficulties may arise in relation to the maintenance of professional boundaries and the termination of the patient-student relationship, particularly if there is a lack of preparation and support available (Ashton, 2016).

\section{Limitations}

In addition to the limitations highlighted at the end of the analysis section there were no co-researchers involved in the data analysis. This may have a negative influence on the credibility of the findings as it removes opportunities for dialogue and agreement in terms of data interpretation and categorisation (Graneheim and Lundman, 2004; Silverman, 2011). Likewise, member checking was not carried out which may have assisted in reducing potential researcher bias by actively involving research participants in checking and confirming the results (Birt, Scott, Caver, Campbell and Walter, 2016). This approach was not taken because there are criticisms and potential difficulties associated with member checking (Bloor, 1997) which were felt to be particularly applicable to the deductive methods used. The study is limited to a relatively small sample of nursing students from one Scottish university and no claim to generalisability is made by the researcher.

\section{Conclusion}

This study highlights factors which play a role in the peripherality or marginality of student nurses within the first placement and the potential implications for their emerging identities. Engagement in the practice of nursing 
work acts as a trigger for learning and has a role in shaping the identity of the student nurse (Grealish and Ranse, 2009). Students' peripheral status within the CoP can support learning, but this appears to require a compliant relationship with the mentor. It also provides access to patients and their visitors in a way that is less available to more central members of the community. Some students experienced marginalisation during the first placement and this was apparent in their interactions with members of the CoP. As suggested by Melincavage (2011) it is important that those whose status is at the periphery of the $\mathrm{CoP}$ are treated respectfully. This will help to promote student learning and is likely to have a positive influence on their emerging identity. The implication of this for those involved in providing pre-registration nurse education is the necessity of effective relationships between university and practice settings. The liaison lecturer is an important part of this relationship as they are well placed to support practice learning and advocate for students (Collington et al., 2012). However, this is reliant upon the liaison lecturer being accessible to both students and the placement area and it does appear that there is scope for greater consistency from the perspective of some students. Addressing this issue may lead to improvements in the support available students, particularly those who are facing barriers to their learning. Given the relevance of CoP to practice learning within nurse education (Morley, 2016) another way to facilitate effective support for students may be through greater inclusion of $\mathrm{CoP}$ theory within mentor education. This would provide mentors with the opportunity to consider how CoP theory can assist them in understanding and evaluating the learning environment they are providing as well as the relevance of key concepts such as peripherality and marginality in relation to the student experience. In addition, it may be useful to provide students with further information which prepares them for the possible benefits and challenges of learning in terms of the relationships with staff, patients and relatives/carers. This could include greater use of input by representatives from practice learning environments along with further introductory information about learning within social contexts. This study has demonstrated that CoP can provide a useful perspective for exploring the experiences of student nurses within their first placement and may be an approach worth pursuing on a larger scale. 
Ashton, K. (2016) Teaching nursing students about terminating professional relationships, boundaries, and social

3 media. Nurse Education Today. 37: 170-172. doi:

Aston, L. and Hallam, P. (2011) Successful mentoring in nursing. Exeter: Learning Matters.

Atkins, S. and Williams, A. (1995) Registered nurses' experiences of mentoring undergraduate nursing students. Journal of Advanced Nursing. 21, 1006-1015.

Baglin, M. and Rugg, S. (2010) Student nurses' experiences of community-based practice placement learning: A qualitative exploration. Nurse Education in Practice. 10: 144-152.

Birt, L., Scott, S., Caver, D., Campbell, C. and Walter, F. (2016) Member checking: A tool to enhance trustworthiness or merely a nod to validation. Qualitative Health Research. doi: 10.1177/1049732316654870

Blackmore, C. (2010) Social Learning Systems and Communities of Practice. London: Springer.

Bloor, M. (1997) Techniques of validation in qualitative research: a critical commentary. In: Miller, G. and Dingwall, R. (Eds.) Context and method in qualitative research (pp.37-50). . London: Sage Publications.

Bradbury-Jones, C., Sambrook, S. and Irvine, F. (2007) The meaning of empowerment for nursing students: a critical incident study. Journal of Advanced Nursing. 59(4): 342-351.

Braun, V. and Clarke, V. (2008) Using thematic analysis in psychology. Qualitative Research in Psychology. 3(2), 77101. doi: $10.1191 / 1478088706 q p 063$ oa

Brinkmann, S. and Kvale, S. (2005) Confronting the ethics of qualitative research. Journal of Constructivist Psychology. 18, 157-181.

Brinkmann, S. and Kvale, S. (2015) Interviews. Learning the craft of qualitative research interviewing. 3rd ed. $\square$ London: Sage Publications.

Burkitt, I., Husband, C., MacKenzie, J., Torn, A. \& Crow, R. (2000) Clinical judgment and nurse education: nursing identities and communities of practice. London: Research Highlights ENB $44 . \square$

Collington, V., Mallik, M., Doris, F. and Fraser, D. (2012) Supporting the midwifery practice-based curriculum: The role of the link lecturer. Nurse Education Today, 32(8): 924-929. doi: 10.1016/j.nedt.2011.09.017

Cook, A. (2009) The Roots of Attrition. In: Cook, A. and Rushton, B. (Eds.) How to Recruit and Retain Higher Education Students (pp. -11). Abingdon: Routledge. $\square$

Creswell, J. (2009) Research Design Qualitative, Quantitative and Mixed Methods Approaches. 3rd ed. $\square$ London: Sage Publications. $\square$

Elo, S. and Kyngas, H. (2008) The qualitative content analysis process. Journal of Advanced Nursing. 62(1), 107-115. doi: $10.1111 / j .1365-2648.2007 .04569 . x$ 
Eraut, M. (2002) Conceptual Analysis and Research Questions: Do the Concepts of 'Learning and Community' and 'Communities of Practice' Provide Added Value? Paper presented at the annual meeting of the American Educational Research Association, New Orleans, LA, 1-5 April.

Eraut, M., Alderton, J., Cole, G. and Senker, P. (2000) Development of knowledge and skills at work. In: Coffield, F. (Ed.) Differing Visions of a Learning Society: Research Findings 1. Bristol: The Policy Press.

Field, D. (2004) Moving from novice to expert - the value of learning in clinical practice: a literature review. Nurse Education Today. 24, 560-565.

Flick, U. (2008) An introduction to qualitative research. London: Sage Publications.

Gibbons, C., Dempster, M. and Moutray, M. (2008) Stress and eustress in nursing students. Journal of Advanced Nursing. 61(3): 282-290.

Gobbi, M. (2010) Learning Nursing in the Workplace Community: The Generation of Professional Capital. In: Blackmore, C. (Ed.) Social Learning Systems and Communities of Practice. London: Springer.

Graneheim, U.H. and Lundman, B. (2004) Qualitative content analysis in nursing research: concepts, procedures and measures to achieve trustworthiness. Nurse Education Today. 24: 105-112.

Gray M \& Smith L (2000) The qualities of an effective mentor from the students nurse's perspective: findings from a longitudinal qualitative study. Journal of Advanced Nursing. 32 (6):1542-1549. $\square$

Grealish, L. and Ranse, K. (2009) An exploratory study of first year nursing students' learning in the clinical workplace. Contemporary Nurse. 33(1), 80-92.

Hamshire, C., Willgoss, T. and Wibberley, C., (2013). Should I stay or should I go? A study exploring why healthcare students consider leaving their programme. Nurse Education Today. 33(8), 889-895.

Hathorn,D., Machtmes,K. $\square$ and Tillman, K. (2009) The lived experience of nurses working with student nurses in the clinical environment. The Qualitative Report. 14(2): 227-244. $\square$

Hoel, H., Giga, S. and Davidson, M. (2007) Expectations and realities of student nurses' experiences of negative behaviour and bullying in clinical placement and the influences of socialization processes. Health Services Management Research. 20(4): 270-278. $\square$

Jokelainen, M., Turunen, H., Tossavainen, K., Jamookeeah, D. and Coco, K. (2011) A systematic review of mentoring nursing students in clinical placements. Journal of Clinical Nursing. 20, 2854-2867. doi: 10.1111/j.13652702.2010.03571.x

Lave, J. and Wenger, E. (1991) Situated Learning: Legitimate Peripheral Participation. Cambridge: Cambridge University Press.

Le May (2009) Communities of Practice in Health and Social Care. Chichester: Blackwell. 
Levett-Jones, T. and Lathlean, J. (2009) 'Don't rock the boat': Nursing students' experiences of conformity and compliance. Nurse Education Today. 29(3), 342-349. doi: http://dx.doi.org/10.1016/j.nedt.2008.10.009

McIntosh, A., Gidman, J. and Smith, D. (2014) Mentors' perceptions and experiences of supporting student nurses in practice. International Journal of Nursing Practice. 30, 360-365.

Melincavage, S. M. (2011) Student nurses' experiences of anxiety in the clinical setting. Nurse Education Today. 31, 785-789. doi:10.1016/j.nedt.2011.05.007

Miller, K., Calder, C., Martin, A., McIntyre, M., Pottinger, I. and Smyth, G. (2008) Quality Enhancement Themes: The First Year Experience. Personal Development Planning in the First Year. $\square$ Mansfield: Quality Assurance Agency for Higher Education. $\square$

Morley, D. (2016) Applying Wenger's communities of practice theory to placement learning. Nurse Education Today. 39, 161-162. doi: 10.1016/j.nedt.2016.02.007

Myall, M., Levett-Jones, T. and Lathlean, J. (2008) Mentorship in contemporary practice: the experiences of nursing students and practice mentors. Journal of Clinical Nursing. 17(14): 1834-1842.

National Health Service Education for Scotland (2008) Quality Standards for Practice Placements. Retrieved from http://www.nes.scot.nhs.uk/education-and-training/by-discipline/nursing-and-midwifery/practiceeducation/quality-management-of-the-practice-learning-environment-\%28qmple\%29/quality-standards-forpractice-placements-\%28revised-2008\%29.aspx.

National Health Service Education for Scotland (2013) The National Nursing and Midwifery Practice Education Facilitator Network. Retrieved from http://www.nes.scot.nhs.uk/media/1887900/pef_review_web.pdf.

Nursing and Midwifery Council (2008) Standards to support learning and assessment in practice. Retrieved from http://www.nmc-uk.org/Educators/Standards-for-education/Standards-to-support-learning-and-assessmentin-practice/Standards-to-support-learning-and-assessment-in-practice-settings-SLAiP/Mentorship/.

O’Driscoll, M., Allan, H. and Smith, P. (2010). Still looking for leadership - Who is responsible for student nurses' learning in practice? Nurse Education Today. 30(3): 212-217.

Ponterotto, J. and Grieger, I. (2007) Effectively Communicating Qualitative Research. The Counselling Psychologist. 35(3): 404-430.

Price, L., Hastie, L., Duffy, K., Ness, V. and McCallum, J. (2011) Supporting students in clinical practice: Preregistration nursing students' views on the role of the lecturer. Nurse Education Today. 31(8): 780-784. doi: 10.1016/j.nedt.2011.04.009

Rodgers, S., Stenhouse, R., McCreadie, M. and Small, P., (2012). Recruitment, selection and retention of nursing and midwifery students in Scottish Universities. Nurse Education Today. 33(11): 1301-1310. 
Royal College of Nursing (2008) Nursing Our Future. An RCN study into the challenges facing today's nursing students in Scotland. Edinburgh: Royal College of Nursing.

Rubin, H. and Rubin, I. (2005) Qualitative Interviewing. The art of hearing data. 2nd ed. London: Sage.

Rubin, H. and Rubin, I. (2012) Qualitative Interviewing. The art of hearing data. 3rd ed. London: Sage.

Sayer, L. (2014) Communities of practice, a phenomenon to explain student development in community nursing. Primary Health Care Research and Development. 15, 430-440. doi:10.1017/S1463423613000455

Sharples, K. (2009) Learning to Learn in Nursing Practice. Exeter: Learning Matters.

Spouse, J. (1998) Learning to nurse through legitimate peripheral participation. Nurse Education Today. 18, 345-351.

Suikkala, A., Leino-Kilpi, H. and Katajisto, J. (2008) Factors related to the nursing student-patient relationship: The students’ perspective. Nurse Education Today. 28, 539-549. doi:10.1016/j.nedt.2007.09.004

Suikkala, A., Leino-Kilpi, H. and Katajisto, J. (2009) Factors related to the nursing student-patient relationship: The patients’ perspective. Scandinavian Journal of Caring Sciences. 625-634. doi: 10.1111/j.14716712.2008.00648.x

The Quality Assurance Agency for Higher Education (2012) UK Quality Code for Higher Education. Part B: Assuring and Enhancing Academic Quality. Chapter B3: Learning and Teaching. Retrieved from http://www.qaa.ac.uk/publications/information-and-guidance/uk-quality-code-for-higher-education-chapterb3-learning-and-teaching .

Thomas, J., Jack, B. and Jinks, A. (2012) Resilience to care: A systematic review and meta-synthesis of the qualitative literature concerning the experiences of student nurses in adult hospital settings in the UK. Nurse Education Today. 32(6), 657-664. doi: http://dx.doi.org/10.1016/j.nedt.2011.09.005

Thrysoe, L., Hounsgaard, L., Bonderup, N. and Wagner, L. (2010) Participating in a community of practice as a prerequisite for becoming a nurse Trajectories as final year nursing students. Nurse Education in Practice. 10: $361-366 . \square$

Wenger, E. (1998) Communities of Practice: Learning, Meaning, and Identity. Cambridge: Cambridge University Press. $\square$ 
Table 1. Questions from the interview guide.

Did you have any expectations prior to your first placement?

How did these expectations compare with the placement itself?

Were there any experiences during the first placement which made you doubt yourself in terms of progressing with your nurse education?

Were there any experiences during the first placement which have made you more confident in terms progressing with your nurse education? 
Table 2. Deductive and inductive categories.

\begin{tabular}{|l|l|l|l|}
\hline Deductive main categories & Inductive sub-categories \\
\hline $\begin{array}{l}\text { Participant experiences of } \\
\text { peripherality. }\end{array}$ & $\begin{array}{l}\text { The mentor as a factor in } \\
\text { experiences of } \\
\text { peripherality. }\end{array}$ & $\begin{array}{l}\text { Other staff as a factor in } \\
\text { experiences of } \\
\text { peripherality. }\end{array}$ & $\begin{array}{l}\text { Patients, carers and } \\
\text { family as a factor in } \\
\text { experiences of } \\
\text { peripherality. }\end{array}$ \\
\hline $\begin{array}{l}\text { Participant experiences of } \\
\text { marginality. }\end{array}$ & $\begin{array}{l}\text { The mentor as a factor in } \\
\text { experiences of marginality. }\end{array}$ & $\begin{array}{l}\text { Other staff as a factor in } \\
\text { experiences of } \\
\text { marginality. }\end{array}$ & $\begin{array}{l}\text { Liaison lecturer as a } \\
\text { factor in experiences of } \\
\text { marginality. }\end{array}$ \\
\hline
\end{tabular}

